\title{
Os Impactos da Adoção de Metodologias Ativas no Desempenho dos Discentes do Curso de Ciências Contábeis de Instituição de Ensino Superior Mineira
}

\begin{abstract}
Resumo
Uma reformulação na educação tem sido discutida pela comunidade científica com a finalidade de atender a novos objetivos nos processos de aprendizagem. É um desafio para as universidades modificarem o seu papel social, agregando novas metodologias de ensino nos seus programas de graduação para se inserirem neste contexto atual. A motivação deste estudo é verificar se a adoção de metodologias ativas de ensino no curso de Ciências Contábeis de uma Instituição de Ensino Superior privada, situada na região da Zona da Mata mineira, contribuiu para o desempenho dos seus discentes, sendo caracterizada como desempenho, nesta pesquisa, a melhoria das notas dos estudantes. As metodologias ativas, atendendo a essa reformulação educacional, estão preocupadas em formar um estudante crítico, capaz de atuar no mercado atual, sujeito a constantes mudanças. O período de estudo compreende os anos entre 2011 e 2014. Buscou-se responder à seguinte questão: Há impacto no desempenho dos discentes do curso de Ciências Contábeis após a implantação de metodologias ativas na IES pesquisada? Para testar a hipótese proposta, utilizou-se o teste de médias T student e métodos de regressão. Os dados analisados foram coletados a partir de documentos cedidos pelos colaboradores da instituição. Os resultados mostram que há evidências de que a utilização das metodologias ativas no curso de Ciências Contábeis contribuíram para o desempenho dos estudantes no período estudado.
\end{abstract}

Palavras-chave: Metodologias ativas. Curso de Ciências Contábeis. Desempenho dos discentes.
Cícero José Oliveira Guerra Mestre em Ciências Contábeis pela Fucape Business School e Professor da Faculdade de Ciências Gerenciais de Manhuaçu (Facig). Contato: Avenida Getúlio Vargas, n. ${ }^{0} 733$. Coqueiro. Manhuaçu - MG, CEP: 36000-000 E-mail: cicero-oli@hotmail.com

\section{Aridelmo José Campanharo} Teixeira

Doutor em Controladoria e Contabilidade pela Universidade de São Paulo e Professor na Fucape Business School. Contato: Avenida Fernando Ferrari . $^{\circ}$ 1358. Boa Vista. Vitória - ES, CEP: 29075-505

E-mail: aridelmo@fucape.br 


\section{Introdução}

A necessidade de uma reformulação educacional nas áreas de ensino superior tem sido discutida em âmbito internacional com a finalidade de definir novos objetivos para o sistema de ensino-aprendizagem, e tal discussão vem ampliando as pesquisas científicas acerca desse assunto (Lapina \& Slaidins, 2014). O desafio das instituições de ensino do século XXI é atender a novas necessidades sociais (Mitre, Siqueira-Batista, Girardi-de-Mendonça, Morais-Pinto, Meirelles, Pinto-Porto, Moreira \& Hoffmann 2008).

Para Mitre et.al. (2008), essas necessidades devem-se ao meio em que estamos vivendo atualmente: constantes mudanças, novas e avançadas tecnologias e percepção de um mundo com relações dinâmicas. Assim, a universidade deveria reconstruir seu papel, a fim de proporcionar conhecimentos amplos e desenvolvimento social (Mitre et. al., 2008; Goñi Zabala, 2006).

Logo, na academia crescem as publicações referentes às novas abordagens de ensino-aprendizagem para atender a esse novo cenário, destacando-se, no Brasil, as metodologias ativas. Pesquisas realizadas com a utilização de metodologias ativas nos cursos de Contabilidade, envolvendo algumas disciplinas como a de Contabilidade Introdutória I, vêm mostrando vantagens em tais metodologias, como a melhora da comunicação, o trabalho em equipe e a satisfação dos docentes (Soares, Araújo \& Leal, 2008; Heagy \& Lehmann, 2005)

Ainda assim, há a necessidade de mais estudos sobre essa temática na literatura, envolvendo mais disciplinas e mais de uma metodologia ativa de ensino-aprendizagem (Stanley \& Marsden, 2012). Para Stanley e Marsden (2012), os cursos de Ciências Contábeis precisam reforçar habilidades que os futuros profissionais devem obter, mas parecem esquecidas.

Convênios com universidades, inclusive brasileiras, têm sido realizados com o propósito de contribuir para o reforço e a inovação do ensino superior no século XXI, como promove o Laspau - órgão afiliado à Universidade Harvard, nos Estados Unidos, com o Science, Technology, Humanity, Engineering and Mathematics (STHEM Brasil) (Sthem, 2015). Salienta-se que o curso de Ciências Contábeis merece atenção pelas seguintes razões: a sua expansão nas últimas décadas; as mudanças na Contabilidade brasileira com a adoção das normas internacionais; e os baixos índices de desempenho em exames nacionais realizados pelos discentes (Mamede, Marques \& Rogers, 2015)

Para isso, levantou-se a seguinte questão de pesquisa: Qual impacto no desempenho dos discentes do curso de Ciências Contábeis após a implantação de metodologias ativas em IES? Nesse contexto, o objetivo deste trabalho é verificar quais impactos a adoção dessas metodologias ativas tem contribuído para o desempenho dos discentes do curso de Ciências Contábeis.

Objeto desta pesquisa, o curso de Ciências Contábeis de uma Instituição de Ensino Superior (IES) privada, situada na Zona da Mata mineira, vem aderindo às metodologias ativas em seus programas de ensino, além de ser membra do STHEM (Sthem, 2015). Espera-se, corroborando os achados de Silva Souza, Iglesias e Pazin-Filho (2014), que as metodologias ativas impactem no desempenho dos discentes do curso de Ciências Contábeis, uma vez que elas buscam capacitá-los a tomar decisões e a ter o controle das tarefas que devem ser realizadas (Mitre et. al., 2008).

Quanto à estrutura deste trabalho, apresenta-se, neste primeiro capítulo, a discussão introdutória da pesquisa, o problema de pesquisa, a motivação para realizar o estudo e seu objetivo. O capítulo dois traz a contribuição da literatura necessária para o desenvolvimento desta pesquisa. Os subtemas serão: Metodologias Ativas de Ensino; Educação Superior e o curso de Ciências Contábeis. O capítulo três contextualiza como ocorreu o processo de adoção das metodologias ativas na IES estudada e os convênios firmados pela IES para a implantação dessa nova metodologia de ensino-aprendizagem.

Já o capítulo quatro constrói a hipótese desta pesquisa. O quinto contempla os aspectos metodológicos do estudo para obter o objetivo anteriormente proposto, bem como a coleta de dados, as variáveis e as técnicas de análise dos dados. O capítulo seis trata da a análise dos resultados, e o sete, as conclusões e considerações finais da pesquisa. 


\section{Referencial Teórico}

\subsection{Metodologias Ativas de Ensino}

As metodologias ativas de ensino-aprendizado são um processo que inclui o discente de forma ativa no ambiente relacionado à sua profissão, ainda na sua formação, estimulando o estudante a buscar respostas de diversos problemas, e isso possibilita que se coloque em prática, já na graduação, sua capacidade de exame, reflexão, além de proporcionar meios que o leve à produção de novas pesquisas (Mitre et. al., 2008).

Por meio de situações reais, ou não, os discentes são capazes de resolver os desafios advindos do meio social em diferentes contextos por meio dos problemas a eles apresentados (Berbel, 2011). A aprendizagem ativa acontece quando o aluno realiza atividades que o levem a pensar sobre o que está fazendo, estando preocupado na resolução de problemas e no desenvolvimento de projetos, seja lendo, escrevendo, perguntando e discutindo (Bonwell \& Eison, 1991; Silberman, 1996).

Para que essas metodologias ativas de ensino possam ser aplicadas em cursos de graduação, existem alguns desafios de estrutura (acadêmica e administrativa) bem como de crenças dos professores e alunos (Wall, Prado \& Carraro, 2008). Faz-se necessário que o indivíduo se empenhe em pensar, raciocinar, observar, refletir independente de qual caminho será usado para provocar a aprendizagem ativa (Barbosa \& Moura, 2014)

Há docentes que defendem a ideia de que os alunos já participam ativamente das aulas simplesmente por estarem envolvidos ao assistirem a uma aula expositiva. Entretanto Meyers e Jones (1993) afirmam que os alunos devem fazer muito mais do que só ouvir o orientador para aprenderem efetivamente. Ainda complementam Nihalani e Saha (2012), os quais defendem a importância de o discente entender ativamente o que está sendo realizado em tarefas para que se fixe melhor o conhecimento, afirmando que a disposição contribui para o entendimento e a aprendizagem.

Na visão de Barbosa e Moura (2014), a diferença entre um ambiente tradicional de ensino para um de aprendizagem ativa é justamente a atitude ativa de pensar em contraste com a atitude passiva, que é associada a métodos tradicionais de ensino. Ainda assim, a capacitação dos docentes com novos métodos de aprendizagem não acontece por meio de decretos regulatórios e não trazem resultados esperados se a visão for apenas sobre o currículo de formação (Barbosa \& Moura, 2014).

Faz-se necessário o envolvimento dos estudantes, os quais serão capazes de construírem conhecimento em grupos e resolver os problemas passados (Gwee, 2009). Na visão de Freire (1996), quanto às metodologias ativas, novos conhecimentos e experiências proporcionam a construção do conhecimento que determina a capacidade de aprender e, ainda, de vencer desafios e resolver problemas. Engajamento e participação ativa são necessários para que se tenha a máxima efetividade do processo ensino-aprendizagem (Souza, 2000).

Com a metodologia ativa, o professor atua como um facilitador para que, trabalhando juntamente com o aluno, os dois obtenham resultados (Madruga et. al., 1996; Cyrilo \& Toralles-Pereira, 2004, citado por Silva Souza, Iglesias, \& Pazin-Filho, 2014; Mitre et. al., 2008). Nota-se que o responsável pela atividade é o docente, no entanto, no método de aprendizagem ativa. ele se adapta ao aprendizado ao nível dos discentes, buscando resultados com eles (Silva Souza, Iglesias, \& Pazin-Filho, 2014).

\subsection{Estudos sobre Metodologias Ativas}

Uma pesquisa realizada por Berbel (2011) discorreu sobre a promoção da autonomia discente promovida pelas metodologias ativas com a finalidade de promover a discussão entre pedagogia e essas metodologias, para apresentar aos educadores e formadores os pontos convergentes entre essas áreas. Seus achados possibilitaram concluir que somente a metodologia em si não é capaz de transformar a educação, mesmo que seja a mais promissora. 
$\mathrm{Na}$ área contábil, na aplicação de métodos ativos em uma disciplina de Contabilidade Introdutória I, uma pesquisa mostrou que não há método capaz de solucionar todos os problemas quanto ao ensino-aprendizagem, nem um que garanta colocação no mercado profissional (Soares et. al., 2008). Entretanto, Soares et. al. (2008) destacaram vantagens com a aplicação, tais como aumento da responsabilidade; estímulo para resolver problemas e para leitura; habilidades para trabalhar-se em equipe; e se comunicar.

Já foram realizados trabalhos em relação ao currículo de Contabilidade, utilizando como métodos modelos tradicionais de avaliação, e outros, utilizando o Problem Based Learning (PBL), o qual apresentou resultados mais positivos e ocasionou maior satisfação dos alunos nas aulas (Heagy \& Lehmann, 2005).

Para Stanley e Marsden (2012), a relevante habilidade de questionar parece esquecida na Contabilidade, fundamental para ela, como é para as Ciências Jurídicas e Médicas. A proposta dos autores estava em levantar uma discussão acerca de uma possível mudança no ambiente de educação do curso de Contabilidade da Universidade QUT, onde se fez questionar a importância de um método de ativo para resolver problemas contábeis. Foram pesquisados apenas os matriculados em uma unidade do curso de Ciências Contábeis por meio de um questionário. Um dos métodos aplicados foi o agrupamento dos alunos para reforçar que devem trabalhar em equipe para a resolução de problemas na Contabilidade. Esses métodos são não estruturados e podem ser comparados na prática (Stanley \& Marsden, 2012).

Soares (2008) destaca que o tema é novo para a área contábil, o que favorece novas pesquisas podendo utilizar diferentes disciplinas, ou todo o semestre de pesquisa para um maior número de estudantes na área de Contabilidade. Conclui-se que o objetivo do estudo foi atingido e que, no tópico explorado, os discentes absorveram conhecimento, melhoraram a comunicação e obtiveram confiança (Soares, 2008). Fazem-se necessárias novas pesquisas no campo da Ciência Contábil, pois a temática ainda é nova nessa área, com a utilização de mais dados, com número maior de disciplinas ou número maior de estudantes para a extensão da discussão (Stanley \& Marsden, 2012; Soares, 2008).

\subsection{Construção da Hipótese de Pesquisa}

Bonwell e Eison (1991) salientam que o processo de aprendizagem precisa ser realizado, colocando o aluno como elemento ativo, de forma engajada, compreendendo que todo ciclo de atividades será mais bem aproveitado quando esse indivíduo está envolvido na tarefa em vez de simplesmente absorver passivamente os conhecimentos.

No que se refere à educação contábil, para graduação, Stanley e Marsden (2012) afirmam que parecem esquecidas, na Contabilidade, as novas metodologias ativas de ensino, e que, assim como para as Ciências Jurídicas e Médicas, é fundamental haver novas pesquisas para que seus achados sobre os métodos ativos aplicados na contabilidade contribuam para a Ciência Contábil.

Segundo Soares (2008), não há um método capaz de solucionar todos os problemas quanto ao ensino-aprendizagem, nem aquele que garanta colocação no mercado profissional, mas que essas metodologias podem trazer resultados satisfatórios para os envolvidos. Corroboram Lapina e Slaidins (2014) que metodologias ativas propostas pela inovação pedagógica, e competências e capacidades de participação são essenciais nesse processo de inovação educacional que se discute atualmente.

Dessa forma, espera-se que as metodologias ativas de ensino - aprendizagem impactem positivamente o desempenho dos discentes do curso de Ciências Contábeis da IES estudada. Assim sendo, serão testadas as seguintes hipóteses:

$\mathrm{H}_{0}$ : Não houve impacto no desempenho dos discentes do curso de Ciências Contábeis após a implantação de metodologias ativas na IES pesquisada.

$\mathrm{H}_{1}$ : Houve impacto no desempenho dos discentes do curso de Ciências Contábeis após a implantação de metodologias ativas na IES pesquisada. 


\section{Metodologia de Pesquisa}

\subsection{Coleta de Dados}

Para atingir os objetivos do estudo, foram utilizados os documentos institucionais dos discentes do curso de Ciências Contábeis da IES pesquisada. Dados como resultado final, frequência, programas e cronograma são arquivados semestralmente, quando se encerra um ciclo de atividades. $O$ ingresso no curso de Ciências Contábeis da IES pesquisada é anual. O total de pontos no ano equivale a 100. O discente deve alcançar uma média de $60 \%$ para ser aprovado.

$\mathrm{O}$ desempenho será medido por meio do teste de média $\mathrm{T}$ de student e análises de regressão. Em um primeiro momento, as análises terão como variável dependente as notas dos discentes. Logo, fazem-se os mesmos testes pela percentagem de faltas dos estudantes.

\subsection{Técnica de Análise: Teste T de Student}

Será realizado um teste de diferenças de médias (Teste T de student) para perceber se há impacto no desempenho dos discentes do curso de Ciências Contábeis após a adoção das metodologias ativas de ensino. No teste, faz-se uma comparação das notas dos estudantes que receberam a metodologia de ensino tradicional com as notas dos estudantes quando receberam as metodologias ativas de ensino. Para a realização do teste de média, consideraram-se apenas as disciplinas que se tornaram ativas no curso de Ciências Contábeis, entre os anos de 2012 e 2014.

Classificaram-se como tratamento as notas auferidas pelos estudantes quando estes receberam as metodologias ativas na sala de aula e controle, quando a aula ministrada foi somente tradicional. O teste T é utilizado quando se têm duas condições e se quer saber se a diferença entre as médias são significantes para uma amostra com número menor de observações (Dancey \& Reidy, 2006).

\subsection{Técnica de Análise: Modelo de Regressão}

A fim de verificar se as metodologias ativas impactaram no desempenho dos discentes do curso de Ciências Contábeis, utilizou-se o modelo de regressão linear, considerando como variáveis dependentes as notas dos discentes nos anos analisados. A equação foi estruturada da seguinte forma:

\footnotetext{
Nota $_{i}=\boldsymbol{\beta}_{\mathbf{0}}+\boldsymbol{\beta}_{\mathbf{1}}$ DdeDisciplina Ativa $+\boldsymbol{\beta}_{2}$ DTempo(Antes e Depois $)+\boldsymbol{\beta}_{3}$ DReprovação+

$\boldsymbol{\beta}_{4}$ DTempo (Antes e Depois).DdeDisciplina Ativa $+\boldsymbol{\beta}_{5}$ DTempo (Antes e Depois). DReprovação + $\boldsymbol{\beta}_{6}$ DdeDisciplina Ativa. DReprovação $+\boldsymbol{\beta}_{7}$ DdeDisciplinaAtiva. DReprovação.DTempo (Antes e Depois) + $\boldsymbol{\beta}_{\mathbf{8}}$ Dgenero $+\boldsymbol{\beta}_{\mathbf{9}}$ Dfies $+\boldsymbol{\beta}_{\mathbf{1 0}}$ Dbolsapref $+\boldsymbol{\beta}_{\mathbf{1 1}}$ Dprouni + $\boldsymbol{\beta}_{12}$ Dsembolsa $+\boldsymbol{\beta}_{13}$ Dtitdocente $+\boldsymbol{\beta}_{\mathbf{1 4}} \%$ faltas $+\boldsymbol{\beta}_{\mathbf{1 5}} \%$ idade $+\boldsymbol{\beta}_{\mathbf{1 6}}$ expdocente $+\boldsymbol{\varepsilon}_{\boldsymbol{i}}$
}

Em que:

Nota: Variável dependente.

$D$ de Disciplina ativa: Variável explicativa binária, assumindo um grupo de disciplinas, em que, se a disciplina passou a ser ativa no curso, recebe 1; caso contrário, 0 .

DTempo (Antes e Depois): Variável explicativa binária assumindo:

1 se o tempo for > ou igual 2012; 0, caso contrário - Para o modelo 2012

1 se o tempo for $>$ ou igual 2013; 0, caso contrário - Para o modelo 2013

1 se o tempo for > ou igual 2014; 0, caso contrário - Para o modelo 2014 
DReproção: Variável binária assumindo o valor 1 , se o discente ficou reprovado; e 0 , caso contrário.

Dgênero: Variável explicativa binária assumindo o valor 1, se o discente for do gênero feminino; e 0 , caso contrário.

Dfies: Variável explicativa binária assumindo o valor 1 , se o discente fez financiamento estudantil; e 0 , caso contrário.

Dbolsapref: Variável explicativa binária assumindo o valor 1 , se o discente é bolsista pela prefeitura local; e 0 , caso contrário.

Dprouni: Variável explicativa binária assumindo o valor 1, se o discente é bolsista pela prefeitura local; e 0 , caso contrário.

Dsembolsa: Variável explicativa binária assumindo o valor 1, se o discente não possui bolsa/convênios; e 0 , caso contrário.

Dtitdocente: Variável explicativa binária assumindo o valor 1, se o docente é mestre ou doutor; e 0 se graduado ou pós-graduado.

\%Faltas: Variável do percentual de faltas dos discentes nas aulas no período estudado.

Idade: Variável explicativa da idade em anos dos discentes.

Expdocente: Variável de experiência dos docentes em anos.

\section{Análise dos Resultados}

\subsection{Contextualização do Processo de Adoção dos Métodos Ativos na IES Pesquisada}

A IES pesquisada é membro do STHEM Brasil, que se preocupa em promover uma educação superior inovadora e de qualidade no Brasil (Sthem, 2015), conveniado ao Programa Acadêmico e Profissional para as Américas (Laspau), dedicado à missão de fortalecer o ensino superior no Hemisfério Ocidental. É um programa sem fins lucrativos, afiliado à Universidade de Harvard, fundado em 1964 (Sthem, 2015).

A adoção das metodologias ativas na IES pesquisada ocorreu, de acordo com informações coletadas pelo pesquisador, pela percepção de que estão surgindo novas abordagens sobre o aprendizado e pelos relatos de outras faculdades que obtiveram sucesso na adoção desse método. Assim sendo, a partir do ano de 2012, as técnicas dessas metodologias ativas de ensino-aprendizagem vêm sendo utilizadas gradativamente em todos os cursos de graduação da instituição.

A IES utiliza, até a presente pesquisa, sete técnicas (todas utilizadas no curso de Ciências Contábeis): Método do Caso, Team-Based Learning (TBL), PBL, Peer-Instruction, Júri Simulado, Metodologias para Projeto, Ensino Audiovisual. Para o curso de Ciências Contábeis, até o ano da pesquisa, cerca de 60\% das disciplinas recebem o método. As aulas tradicionais acontecem normalmente, e o professor pode determinar se utilizará parte da aula ativa ou todo o período de aula, dependendo da atividade a ser dada. Logo, as metodologias ativas são complementares às aulas expositivas (aulas tradicionais + aulas ativas).

\subsection{Caracterização da Amostra}

Com a finalidade de perceber se a metodologia ativa impactou no desempenho dos discentes do curso de Ciências Contábeis da IES, levantaram-se variáveis que caracterizavam esses indivíduos. Os resultados abaixo estão demonstrados. 
Tabela 1

\section{Estatística Descritiva Referente aos Alunos}

\begin{tabular}{|c|c|c|c|c|c|c|c|c|c|c|c|}
\hline & & \multirow{2}{*}{\multicolumn{8}{|c|}{ Ano letivo }} & \multirow{3}{*}{\multicolumn{2}{|c|}{ Total Geral }} \\
\hline & & & & & & & & & & & \\
\hline & & \multicolumn{2}{|c|}{2011} & \multicolumn{2}{|c|}{2013} & \multicolumn{2}{|c|}{2013} & \multicolumn{2}{|c|}{2014} & & \\
\hline & & $\mathrm{N}$ & $\%$ & $\mathrm{~N}$ & $\%$ & $\mathrm{n}$ & $\%$ & $\mathrm{~N}$ & $\%$ & $\mathrm{n}$ & $\%$ \\
\hline \multirow{2}{*}{ Gênero } & Feminino & 93 & $60 \%$ & 80 & $62 \%$ & 87 & $59 \%$ & 108 & $63 \%$ & 368 & $61 \%$ \\
\hline & Masculino & 63 & $40 \%$ & 49 & $38 \%$ & 60 & $41 \%$ & 63 & $37 \%$ & 235 & $39 \%$ \\
\hline \multirow{5}{*}{ 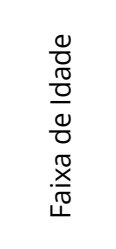 } & De $19-24$ anos & 37 & $24 \%$ & 57 & $44 \%$ & 83 & $57 \%$ & 106 & $62 \%$ & 283 & $47 \%$ \\
\hline & De $24-29$ anos & 65 & $42 \%$ & 49 & $38 \%$ & 44 & $30 \%$ & 46 & $27 \%$ & 204 & $34 \%$ \\
\hline & De $29-34$ anos & 34 & $22 \%$ & 17 & $13 \%$ & 11 & $8 \%$ & 14 & $8 \%$ & 76 & $13 \%$ \\
\hline & De 34 - 39 anos & 13 & $8 \%$ & 5 & $4 \%$ & 8 & $5 \%$ & 4 & $2 \%$ & 30 & $5 \%$ \\
\hline & Acima de 39 anos & 7 & $5 \%$ & 1 & $1 \%$ & 1 & $1 \%$ & 1 & $1 \%$ & 10 & $2 \%$ \\
\hline \multirow{2}{*}{$\begin{array}{l}\text { Ensino } \\
\text { Básico }\end{array}$} & Ensino Privado & 4 & $3 \%$ & 4 & $3 \%$ & 6 & $4 \%$ & 7 & $4 \%$ & 21 & $3 \%$ \\
\hline & Ensino Público & 152 & $97 \%$ & 125 & $97 \%$ & 141 & $96 \%$ & 164 & $96 \%$ & 582 & $97 \%$ \\
\hline \multirow{5}{*}{ 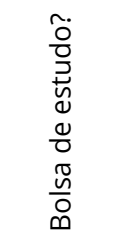 } & Bolsa Prefeitura & 16 & $10 \%$ & 15 & $12 \%$ & 11 & $8 \%$ & 17 & $10 \%$ & 59 & $10 \%$ \\
\hline & Fies & 22 & $14 \%$ & 35 & $27 \%$ & 47 & $32 \%$ & 37 & $22 \%$ & 141 & $23 \%$ \\
\hline & Prouni & 19 & $12 \%$ & 17 & $13 \%$ & 22 & $15 \%$ & 27 & $16 \%$ & 85 & $14 \%$ \\
\hline & Sem bolsa & 69 & $44 \%$ & 40 & $31 \%$ & 47 & $32 \%$ & 65 & $38 \%$ & 221 & $37 \%$ \\
\hline & Outros benefícios & 30 & $19 \%$ & 22 & $17 \%$ & 20 & $14 \%$ & 25 & $15 \%$ & 97 & $16 \%$ \\
\hline \multicolumn{2}{|c|}{ Total Geral } & 156 & $100 \%$ & 129 & $100 \%$ & 147 & $100 \%$ & 171 & $100 \%$ & 603 & $100 \%$ \\
\hline
\end{tabular}

Fonte: elaborado pelos autores

As amostras contêm um total geral de 603 alunos distribuídos entre os anos ativos e não ativos. Ao analisarmos a variável "Gênero", percebemos que o gênero feminino é atribuído $61 \%$ do total geral; já o gênero masculino, 39\% do total, analisando todos os anos estudados. Quanto às faixas etárias, em média, percebe-se que aproximadamente $80 \%$ das amostras são compostas por alunos com idade de 19 a 29 anos, e os demais $20 \%$ de 29 a acima de 39 anos.

A adoção pelo Fies soma um percentual médio de 23\%, e o ano de 2013 foi o que apresentou maior percentagem - 33\% dos discentes aderiram ao financiamento nesse ano (um total de 47 estudantes). Em Prouni, no total geral, apresentou 14\% de adoção estudantil, e 2014 apresentou o maior percentual - 16\% (um total de 27 estudantes).

A variável "Outros Benefícios" contempla convênios empresariais e demais bolsas, como parentesco; programas internos e olimpíadas, nos quais o discente tem um percentual de desconto acordado com a instituição. Nos anos analisados, podemos perceber que esses benefícios representam, em média, 16\% do total de bolsas de estudo e financiamentos analisados.

O ano de 2014 teve o maior número de descontos concedidos, contemplando 25 discentes do curso de Contabilidade. Constata-se que os ingressantes na IES estudada vieram de escola pública. Esse público é mais representativo que os ingressantes de escola privada, os quais constituem apenas $3 \%$ do total geral de discentes. Um total de 603 estudantes, apenas 21 formaram-se no ensino médio pelo regime particular de ensino. Na Tabela 2, a seguir, apresenta-se a estatística que descreveu as características dos docentes da IES neste período. 
Tabela 2

Estatística Descritiva Referente aos Professores

\begin{tabular}{|c|c|c|c|}
\hline Ano & Titulação do Professor & $\mathbf{N}$ & $\begin{array}{c}\text { Tempo de experiência em } \\
\text { anos (Média) }\end{array}$ \\
\hline \multirow{4}{*}{2011} & Graduação & 5 & 8,20 \\
\hline & Pós-Graduação & 2 & 3,00 \\
\hline & Mestrado & 11 & 8,55 \\
\hline & Total & 18 & 6,00 \\
\hline \multirow{5}{*}{2012} & Graduação & 2 & 24,00 \\
\hline & Pós-Graduação & 5 & 4,00 \\
\hline & Mestrado & 10 & 8,20 \\
\hline & Doutorado & 1 & 8,00 \\
\hline & Total & 18 & 3,00 \\
\hline \multirow{5}{*}{2013} & Graduação & 2 & 11,00 \\
\hline & Pós-Graduação & 5 & 9,00 \\
\hline & Mestrado & 12 & 7,56 \\
\hline & Doutorado & 1 & 8,13 \\
\hline & Total & 20 & 5,00 \\
\hline \multirow{6}{*}{2014} & Graduação & 2 & 6,00 \\
\hline & Pós-Graduação & 8 & 6,25 \\
\hline & Mestrado & 11 & 7,95 \\
\hline & Doutorado & 1 & 11,00 \\
\hline & Total & 22 & 6,00 \\
\hline & Geral & 42 & 7,95 \\
\hline
\end{tabular}

Fonte: elaborado pelos autores

Ao se tratar das características do corpo docente, identificou-se a titulação do professor, o número de professores para aquele ano e a média de tempo de experiência, em anos, que eles têm no meio educacional.

No ano de 2011, de um total de 18 docentes, mais de 60\% obtinham a titulação de mestrado com o maior número de anos de experiência na média, em relação aos demais do mesmo ano. No ano de 2012, embora a titulação de mestre novamente tenha se destacado (10 professores), a experiência média em anos sobressaiu com professores portadores apenas do bacharelado - dois discentes, com vinte e quatro anos de experiência. Nesse ano, um profissional com doutorado fez parte do quadro de docentes da instituição.

Já no ano de 2013, foram contratados mais dois professores com a titulação de mestrado, passando de dez para doze. Manteve-se o número de graduados com uma experiência média de trabalho docente de $11 \%$; pós-graduado, com 9,00\%; mestrado e doutorado, com 7,56\% e 8,13\%, respectivamente. Em 2014, o número de pós-graduados passou de cinco do ano anterior para oito, entretanto, a experiência dos docentes pós-graduados caiu de $9,00 \%$ para $6,25 \%$. Nesse ano, embora o número de mestres tenha caído (em relação ao ano anterior), a experiência docente em anos desse perfil aumentou. Manteve-se o profissional com doutorado, aumentando sua experiência docente. 


\subsection{Dos Resultados do Teste de Média}

A Tabela 3 apresenta as médias e o desvio - padrão das notas dos estudantes nos anos de 2011 a 2014, com base no levantamento das notas registradas das disciplinas que se tornaram ativas na IES.

Tabela 3

Média, Desvio Padrão E Estatística T - Variáveis Nota

\begin{tabular}{|c|c|c|c|c|c|c|c|c|c|}
\hline \multicolumn{8}{|c|}{ Grupo } & \multirow{3}{*}{$\begin{array}{c}\begin{array}{c}\text { Test F } \\
\text { variância }\end{array} \\
\text { p-valor }\end{array}$} & \multirow{3}{*}{$\begin{array}{c}\text { Test t para } \\
\text { média } \\
\text { p-valor }\end{array}$} \\
\hline \multirow[b]{2}{*}{ Ano } & \multirow[b]{2}{*}{ Disciplina } & \multicolumn{3}{|c|}{$\begin{array}{c}\text { Controle } \\
\text { (antes da Met. Ativa) }\end{array}$} & \multicolumn{3}{|c|}{$\begin{array}{c}\text { Tratamento } \\
\text { (depois da Met. Ativa) }\end{array}$} & & \\
\hline & & $N($ nota $)$ & Média & DP & $N($ nota) & Média & DP & & \\
\hline \multirow{8}{*}{2012} & $\begin{array}{l}\text { Comportamento } \\
\text { Organizacional }\end{array}$ & 30 & 64,55 & 21,21 & 102 & 66,87 & 13,70 & 0,044 & 0,478 \\
\hline & Contabilidade Gerencial & 24 & 74,56 & 8,53 & 60 & 62,72 & 17,11 & 0,134 & $0,002 * * *$ \\
\hline & Controladoria & 46 & 70,66 & 12,62 & 77 & 65,10 & 7,82 & 0,226 & $0,003 * * *$ \\
\hline & Filosofia e Ética & 25 & 71,78 & 7,77 & 87 & 70,20 & 14,19 & 0,318 & 0,595 \\
\hline & Laboratório Contábil & 46 & 93,63 & 5,92 & 77 & 77,94 & 16,85 & 0,000 & $0,000 * \star *$ \\
\hline & Matemática & 40 & 74,40 & 11,48 & 129 & 74,27 & 15,34 & 0,120 & 0,962 \\
\hline & Metodologia De Pesquisa & 40 & 67,72 & 22,13 & 121 & 65,02 & 18,21 & 0,197 & 0,444 \\
\hline & Total Geral 2012 & 856 & 67,99 & 17,55 & 199 & 69,47 & 15,55 & 0,168 & 0,275 \\
\hline \multirow{9}{*}{2013} & $\begin{array}{l}\text { Contabilidade Do } \\
\text { Agronegócio }\end{array}$ & 67 & 72,85 & 13,14 & 58 & 79,86 & 14,03 & 0,998 & $0,005^{* * *}$ \\
\hline & Economia & 70 & 66,23 & 19,49 & 89 & 72,26 & 12,75 & 0,111 & $0,020 *$ \\
\hline & Estatística Básica & 71 & 63,75 & 23,14 & 96 & 67,49 & 19,10 & 0,163 & 0,255 \\
\hline & $\begin{array}{l}\text { Legislação Social E } \\
\text { Trabalhista }\end{array}$ & 50 & 70,82 & 6,75 & 59 & 73,58 & 9,46 & 0,045 & $0,088^{*}$ \\
\hline & Sistemas Contábeis & 55 & 75,79 & 17,12 & 63 & 65,62 & 12,88 & 0,012 & $0,000 * * *$ \\
\hline & Teoria Da Contabilidade & 50 & 66,90 & 13,02 & 60 & 64,60 & 12,80 & 0,987 & 0,354 \\
\hline & $\begin{array}{l}\text { Tópicos Contemporâneos } \\
\text { em Contabilidade }\end{array}$ & 67 & 69,65 & 11,16 & 56 & 66,77 & 12,92 & 0,795 & 0,187 \\
\hline & Contabilidade Avançada & 97 & 65,29 & 18,31 & 38 & 58,86 & 18,07 & 0,704 & $0,067^{*}$ \\
\hline & Total Geral 2013 & 745 & 68,54 & 17,48 & 435 & 70,70 & 14,09 & 0,004 & $0,028 * *$ \\
\hline \multirow{9}{*}{2014} & $\begin{array}{l}\text { Estatística E Cálculo } \\
\text { Autuarial }\end{array}$ & 97 & 70,26 & 18,58 & 42 & 72,55 & 13,72 & 0,338 & 0,473 \\
\hline & $\begin{array}{l}\text { Instituições De Direito } \\
\text { Público E Privado }\end{array}$ & 94 & 75,50 & 14,17 & 37 & 80,73 & 8,81 & 0,326 & $0,039 *$ \\
\hline & Teoria Da Administração & 121 & 63,00 & 17,14 & 52 & 62,29 & 21,27 & 0,420 & 0,815 \\
\hline & Sociologia Organizacional & 97 & 74,44 & 15,66 & 38 & 80,45 & 10,74 & 0,176 & $0,032 * \star$ \\
\hline & Contabilidade Introdutória I & 123 & 73,17 & 24,80 & 52 & 66,66 & 19,18 & 0,113 & $0,092^{*}$ \\
\hline & Contabilidade Introdutória II & 112 & 61,39 & 24,24 & 50 & 57,68 & 18,99 & 0,294 & 0,339 \\
\hline & $\begin{array}{l}\text { Direito Comercial e } \\
\text { Societário }\end{array}$ & 95 & 68,23 & 16,02 & 37 & 72,24 & 10,67 & 0,662 & 0,162 \\
\hline & Contabilidade de Custos & 96 & 62,21 & 22,95 & 36 & 78,22 & 9,38 & 0,014 & $0,000 * * *$ \\
\hline & Total Geral 2014 & 458 & 68,07 & 16,30 & 882 & 68,72 & 17,06 & 0,314 & 0,502 \\
\hline
\end{tabular}

$*, * *, * * *$ significativo ao nível de $10 \%, 5 \%$ e $1 \%$ respectivamente.

Fonte: elaborado pelos autores. 
Por meio dos resultados, é possível identificar, em uma análise geral, que apenas disciplinas que receberam as metodologias ativas no ano de 2013 apresentaram uma diferença de médias significativa, ao nível de 5\%, na comparação das suas médias de tratamento e controle. Ao fazermos uma observação individual, por disciplina, percebemos que, das vinte e três disciplinas ativas, obtivemos doze resultados significativos a 1, 5 ou 10\% de significância. No entanto, desses resultados, seis disciplinas apresentaram resultados médios de notas menores quando as aulas foram ministradas com as metodologias ativas de ensino, ainda, quatro dessas a $1 \%$ de significância.

Dessa forma, subentende-se que os estudantes, quando submetidos às disciplinas com metodologias ativas de ensino, diminuíram suas notas em relação aos estudantes em métodos tradicionais. As disciplinas que tiveram um resultado de notas inferior quando ministradas com as metodologias ativas foram: Contabilidade Gerencial, Controladoria, Laboratório Contábil, Sistemas Contábeis, Contabilidade Avançada e Contabilidade Introdutória I.

Das disciplinas que obtiveram resultados melhores com as metodologias ativas apenas duas delas são as que envolvem diretamente a Contabilidade: Contabilidade do Agronegócio e Contabilidade de Custos, ambas significantes ao nível de $1 \%$. As demais, que deram resultados melhores quando aplicadas as metodologias ativas, ao nível de 5 a 10\%, foram: Economia, Legislação Social e Trabalhista, Instituições de Direito Público e Privado e Sociologia Organizacional.

Mesmo apresentando esses resultados, construiu-se o modelo de regressão para perceber o comportamento das notas dos discentes, quando receberam as metodologias ativas, e quando não, no período de tempo estudado com a inserção de variáveis de controle.

\subsection{Das Análises de Regressão}

Para o desenvolvimento do modelo de regressão, foram utilizadas variáveis que, como já apresentadas no decorrer deste capítulo, podem influenciar o desempenho dos indivíduos que participam de aulas com metodologias ativas de ensino-aprendizagem.

Os pressupostos que validam os modelos regressões foram satisfatórios: no ajuste geral pela estatística F (p-valor), teste de independência (Durbin Watson) e normalidade dos resíduos.

\subsubsection{Análise dos anos de 2012 a 2014}

Por meio dos resultados apresentados na Tabela 04, percebemos que durante os anos da pesquisa, de modo geral, as notas dos discentes, independente de associação com as metodologias ativas, historicamente, já estavam caindo, indicando queda no desempenho dos estudantes antes da implantação das metodologias ativas nas disciplinas. É possível validar essa afirmação observando a Dummy "Tempo" nos anos da pesquisa. Evidencia-se assim que, a partir dos anos estudados, as notas dos discentes reduziram independente da metodologia aplicada.

Analisando separadamente o modelo de regressão de 2012, vimos pelos resultados da Dummy de "Disciplina Ativa" que, quando as disciplinas receberam as metodologias ativas, a pontuação dos estudantes aumentou e que, a partir de 2013 e 2014, o desempenho caiu. Entretanto, ao associarmos as disciplinas que receberam as metodologias ativas com o tempo, relacionados pela Dummy "Tempo "Disciplina Ativa", verifica-se que, a partir de 2012, quando as disciplinas foram ministradas com as novas metodologias, as notas dos discentes caíram mais do que quando eram ministradas apenas tradicionalmente. Com base nesse resultado, podemos assumir que, a partir desse ano, as disciplinas com metodologias ativas reduziram ainda mais o desempenho dos estudantes de Contabilidade, com a maior queda no desempenho após sua adoção entre todos os anos. 
A partir do ano seguinte, percebendo os resultados do modelo de 2013, vimos que, com a associação do tempo com as disciplinas ativas, as notas dos discentes não foram estatisticamente significantes. Ainda assim, ao se analisar de maneira geral, a partir desse ano, observamos que para a variável Dummy de "Disciplina Ativa" e Dummy "Tempo" as notas dos discentes diminuíram novamente. No entanto, podemos assumir, com base nos números auferidos, que, a partir do ano de 2013, as disciplinas que receberam as metodologias ativas em função do tempo estão no mesmo patamar das que não receberam as metodologias tradicionais, ou seja, para esse ano, o desempenho dos discentes, com as metodologias ativas, pode não ter piorado nas disciplinas, mas também não melhorou.

Especificamente para os reprovados, vimos que, a partir de 2013, independente da metodologia aplicada, os reprovados auferiram notas melhores, mesmo não tendo sido aprovados nas disciplinas. No entanto, quando receberam as metodologias ativas de ensino, a nota média reduziu na mesma proporção, conforme apresenta a interação Dummy de "Disciplina Ativa” Dummy "Reprovação” e Dummy "Tempo", o que nos leva a afirmar novamente que, para esse modelo, as metodologias ativas não melhoraram o desempenho dos discentes, e a queda foi equivalente à do desempenho sem as metodologias ativas.

Já para o modelo 2014, quando as disciplinas ministradas com as metodologias ativas foram associadas à Dummy "Tempo", percebemos um aumento no desempenho dos estudantes de contabilidade, entretanto, independente do tempo, quando as disciplinas foram ministradas de forma ativa, conforme apresenta a Dummy de "Disciplina Ativa", o desempenho caiu. Ainda, por meio da interação Dummy de "Disciplina Ativa”*, Dummy "Reprovação"^ e Dummy "Tempo", a partir daí identificamos queda no desempenho dos discentes reprovados que receberam as metodologias ativas a partir desse ano.

Para o modelo de 2014, podemos evidenciar que, com a aplicação das metodologias ativas nas salas de aula, não se obteve melhora no desempenho dos alunos. Comparados os números desse modelo com os de 2013, vimos que as notas dos discentes, mesmo os reprovados, que receberam as metodologias ativas de ensino, mantiveram-se constantes, e que as notas apuradas pelas disciplinas tradicionais continuaram caindo.

Embora o desempenho não tenha melhorado nesse último ano, ele não piorou com a utilização das metodologias, o que nos leva a evidenciar que, ao longo do processo, as metodologias ativas vieram ganhando maturação na sua aplicabilidade, e que, por esse motivo, possa se ter, em 2014, um melhor resultado do cenário geral.

Conhecendo os resultados do desempenho dos discentes de Ciências Contábeis da IES estudada pela variável "dependente nota" e apoiado nos achados de Cornachione Junior, Cunha, De Luca e Ott (2010), os quais identificaram que a maioria dos estudantes de Ciências Contábeis consideram o esforço próprio como uma das causas do sucesso do bom desempenho, o pesquisador realizou novamente um teste de regressão linear, considerando agora a variável \% de faltas (variável de controle que contribuiu para o encontro dos resultados acima). 
Tabela 4

\section{Resultados da Regressão Múltipla}

\begin{tabular}{|c|c|c|c|}
\hline \multicolumn{4}{|c|}{ Modelo de Regressão - Variável Dependente Nota } \\
\hline & 2012 & 2013 & 2014 \\
\hline & B/p-valor & B/p-valor & B/p-valor \\
\hline Constante & $75,092^{* * *}$ & $74,322^{* \star *}$ & $74,063 * \star \star$ \\
\hline Dummy de Disciplina Ativa & $1,872^{*}$ & $-0,852^{*}$ & $-1,460 * * *$ \\
\hline Dummy Tempo (Antes e depois) & $-2,031 * * *$ & $-1,552^{\star * *}$ & $-42,436 * * *$ \\
\hline Dummy Reprovação & $-48,731 * \star \star$ & $-42,755^{\star * *}$ & $-42,436 * * *$ \\
\hline $\begin{array}{l}\text { DummyTempo (Antes e depois)* Dummy de } \\
\text { Disciplina Ativa }\end{array}$ & $-2,872 * \star \star$ & 0,305 & $2,160 * * *$ \\
\hline $\begin{array}{l}\text { DummyTempo (Antes e depois) *Dummy } \\
\text { Reprovação }\end{array}$ & $11,134 * * *$ & $3,599 * * *$ & $2,774 * *$ \\
\hline Dummy de Disciplina Ativa* Dummy Reprovação & 3,348 & $3,599 *$ & $7,632 * * *$ \\
\hline $\begin{array}{l}\text { Dummy de Disciplina Ativa* Dummy Reprovação* } \\
\text { Dummy Tempo (Antes e depois) }\end{array}$ & $-4,474$ & $-5,746 * \star$ & $-7,336 * * *$ \\
\hline Dummy Gênero & $0,560 *$ & $0,525^{*}$ & $0,589 *$ \\
\hline Dummy Fies & $0,092 *$ & $-1,711 * * \star$ & $-1,801 * * *$ \\
\hline Dummy Bolsa Prefeitura & $-0,091$ & $-0,191$ & $-0,101$ \\
\hline Dummy Prouni & 6,100 & $6,026 * * *$ & $5,942 * * *$ \\
\hline Dummy sem bolsa & $-0,511$ & $-0,440$ & $-0,474$ \\
\hline Dummy Titulação Docente & $-1,210 * * *$ & $-1,583^{* * *}$ & $-1,627 * \star *$ \\
\hline$\%$ de Faltas & $-0,349 * \star *$ & $-0,362 * * *$ & $-0,367 * * \star$ \\
\hline Idade & $0,092 * \star \star$ & $0,109 * * *$ & $0,117 * \star \star$ \\
\hline Experiência Docente & $-1,060 * \star *$ & $-1,450 * * *$ & 0,650 \\
\hline
\end{tabular}

$*, * *, * * *$ significativo ao nível de $10 \%, 5 \%$ e $1 \%$ respectivamente.

Fonte: Elaborado pelos autores.

O intuito é perceber o comportamento dos discentes também com as metodologias ativas de ensino pela variação do percentual de faltas, pois a frequência deles nas aulas pode ser compreendida como $o$ interesse quando foram ministradas com as metodologias ativas de ensino. Assim sendo, utilizamos o modelo de regressão anteriormente apresentado, no qual a variável dependente passa a ser “\% Faltas", e "Nota" assume uma variável de controle.

\subsection{Análises dos anos de 2012 a 2014 \% de Faltas com a Variável Dependente}

Quando assumimos a variável “\%Faltas" como variável dependente do modelo, conseguimos capturar os seguintes efeitos: a partir do ano de 2012, por meio da interação Dummy Tempo* e Dummy de Disciplina Ativa, percebemos que, recebendo as disciplinas com as metodologias ativas de ensino, as faltas dos discentes diminuíram em relação aos que receberam aulas apenas tradicionais. Ainda, quando associamos as variáveis Dummy de Disciplina Ativa*, Dummy Reprovação* e Dummy Tempo, que apresentam os alunos reprovados que receberam as disciplinas com metodologias ativas a partir do ano de 2012, identificamos que as suas faltas também caíram, ou seja, quando eles participaram das aulas com metodologias ativas, podemos assumir, que a partir de 2012, o número de presentes na sala de aula aumentou, mesmo estando reprovados por nota. 
Com a interação Dummy Tempo* e Dummy de Disciplina Ativa, vimos que o percentual (\%) de faltas dos discentes também diminuiu, subentendendo-se que, quando receberam as metodologias ativas a partir desse ano, o percentual médio de faltas dos discentes também reduziu. A interação Dummy de Disciplina Ativa*, Dummy Reprovação* e Dummy 2013 demonstrou que as faltas dos discentes reprovados que receberam as metodologias ativas de ensino a partir do ano de 2013 também diminuiu.

Independente do tempo, no modelo de 2014, vimos, por meio da Dummy Ativa, que os alunos que receberam as metodologias ativas reduziram o percentual de faltas nessas aulas. Com a interação DummyTempo* e Dummy de Disciplina Ativa percebemos que, quando os discentes receberam as disciplinas com as metodologias ativas de ensino, a partir de 2014, suas faltas diminuíram se comparadas com os discentes que não receberam. No modelo de 2014, vimos ainda que, independente do ano por meio da interação Dummy Disciplina Ativa* e Dummy Reprovação, os alunos reprovados e os que receberam as metodologias ativas aumentaram o percentual de faltas nas aulas, entretanto, quando associamos a variável tempo, por meio da interação Dummy de Disciplina Ativa*, Dummy Reprovação* e Dummy Tempo, novamente presenciamos que, mesmo reprovados, o percentual de faltas desses alunos caiu quando receberam disciplinas com metodologias ativas.

Tabela 5

\section{Resultados da Regressão Múltipla}

\begin{tabular}{|c|c|c|c|}
\hline \multicolumn{4}{|c|}{ Modelo De Regressão - Variável Dependente \%Faltas } \\
\hline & 2012 & 2013 & 2014 \\
\hline & B/p-valor & B/p-valor & B/p-valor \\
\hline Constante & $14,651 * * *$ & $15,082^{* \star *}$ & $15,924 * * *$ \\
\hline Dummy de Disciplina Ativa & 0,650 & 0,101 & $-0,427^{\star}$ \\
\hline Dummy Tempo (Antes e depois) & $0,579 * *$ & 0,382 & $-0,479 *$ \\
\hline Dummy Reprovação & $8,318 * \star *$ & $6,031 * \star \star$ & $4,947 * \star *$ \\
\hline $\begin{array}{l}\text { Dummy Tempo (Antes e depois)^Dummy de } \\
\text { Disciplina Ativa }\end{array}$ & $-1,655^{* \star *}$ & $-1,343 * \star \star$ & $-1,114 * \star$ \\
\hline $\begin{array}{l}\text { Dummy Tempo (Antes e depois) *Dummy } \\
\text { Reprovação }\end{array}$ & $-2,427 * \star \star$ & 0,827 & $4,540 * \star \star$ \\
\hline Dummy de Disciplina Ativa* Dummy Reprovação & 1,209 & 1,691 & $-1,755^{\star \star}$ \\
\hline $\begin{array}{l}\text { Dummy de Disciplina Ativa* Dummy Reprovação* } \\
\text { DummyTempo (Antes e depois) }\end{array}$ & $-6,596 * \star \star$ & $-9,763 * \star \star$ & $-9,775^{* \star *}$ \\
\hline Dummy Gênero & $-0,736 * \star \star$ & $-0,737 * \star \star$ & $-0,768 * \star \star$ \\
\hline Dummy Fies & $-0,589 *$ & $-0,601 *$ & $-0,779 * *$ \\
\hline Dummy Bolsa Prefeitura & $-0,586$ & $-0,579$ & $-0,492$ \\
\hline Dummy Prouni & $0,615^{*}$ & $0,661 *$ & $0,664^{\star}$ \\
\hline Dummy sem bolsa & $-0,846 * \star \star$ & $-0,837 * \star \star *$ & $-0,831 * \star \star *$ \\
\hline Dummy Titulação Docente & $-2,289 * \star \star$ & $-2,349 * \star \star$ & $-2,425 * \star \star$ \\
\hline$\%$ de Faltas & $-0,141 * \star \star *$ & $-0,144 * \star \star$ & $-0,146 * \star \star$ \\
\hline Idade & $0,125 * \star *$ & $0,124 * * \star$ & $0,114 * \star *$ \\
\hline Experiência Docente & $-0,530 * \star \star$ & $-0,86 * \star \star$ & $-0,410 * \star \star$ \\
\hline
\end{tabular}

$*, * \star, * * \star$ significativo ao nível de $10 \%, 5 \%$ e $1 \%$ respectivamente.

Fonte: elaborado pelos autores. 
As figuras 1 e 2 representam a ilustração do comportamento das notas e do \%Faltas dos discentes do curso de Ciências Contábeis, antes e após a adoção das metodologias ativas de ensino, como descrito acima.

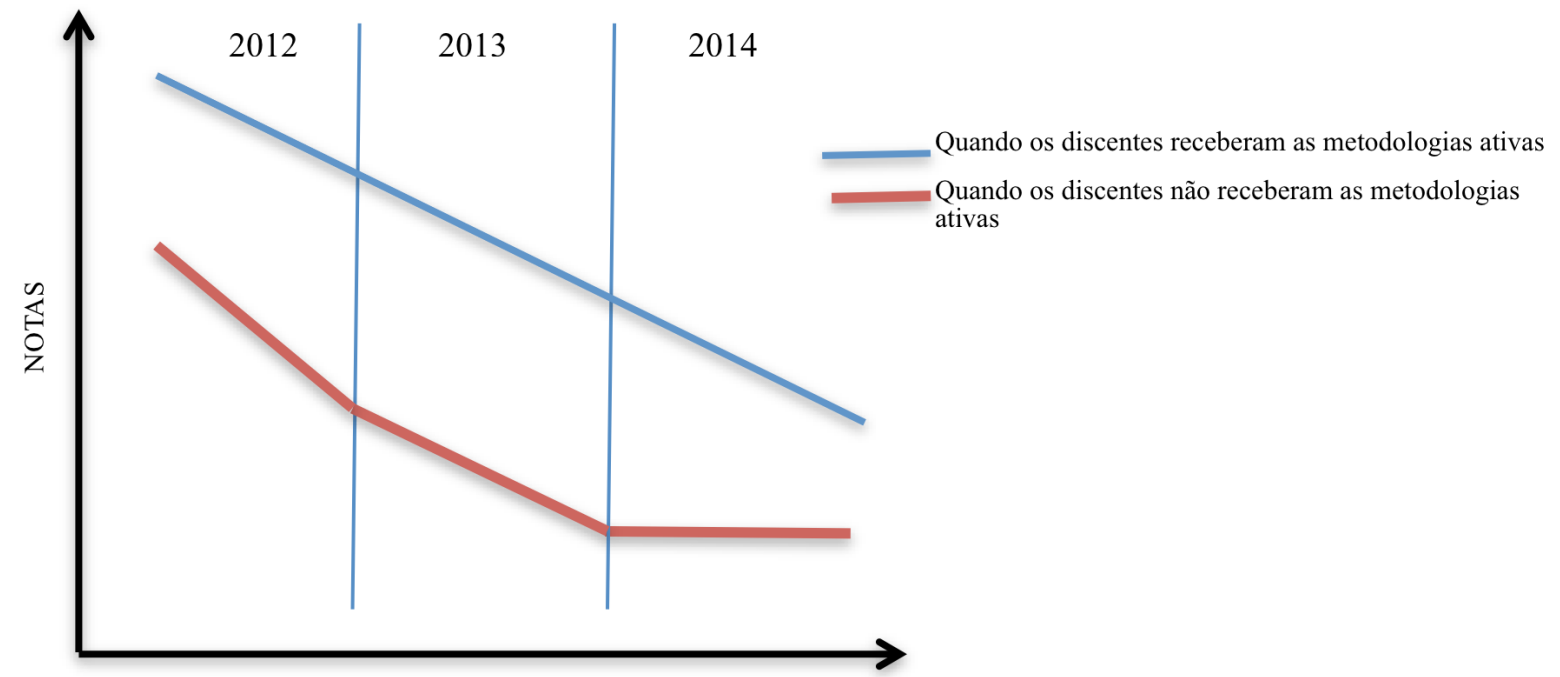

Figura 1. Comportamento das notas dos discentes no tempo da pesquisa.

Fonte: elaborado pelos autores.

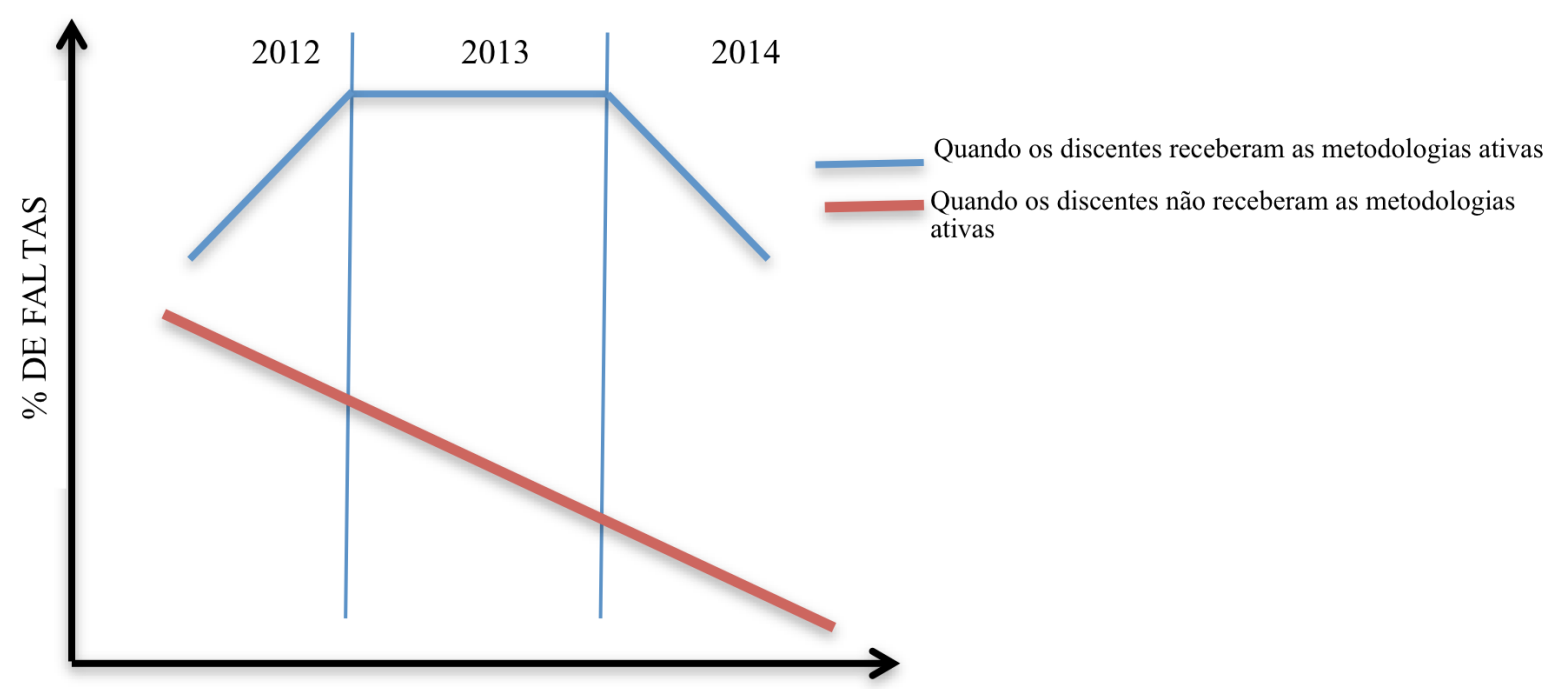

Figura 2. Comportamento do percentual de faltas dos discentes no tempo da pesquisa.

Fonte: elaborado pelos autores.

Após a apresentação dos resultados dos testes de Regressão, embasados na literatura, podemos afirmar que os resultados encontrados neste estudo podem ser explicados por fatores como: o controle do estudante; o esforço que este aplica sobre as atividades; humor; a dificuldade de realização das tarefas; doença; e a instabilidade (de que o aluno pode mudar seu interesse ao longo do tempo), pois esses são fatores determinantes para que os discentes tenham sucesso, ou não, no desempenho estudantil (Weiner, 1982; Cornachione Junior et. al., 2010). 
Bzuneck (2005) afirma ainda que problemas motivacionais estão ligados à aprendizagem dos estudantes e têm relação com o sucesso deles. O ambiente da sala de aula, ações do professor, o não envolvimento do aluno e o uso incorreto das estratégias de aprendizagem também podem estar relacionados aos achados nesta pesquisa, como confirmam Guimarães (2003); Ruiz (2005); Zenorini e Santos (2003).

Quanto aos melhores desempenhos de estudantes do gênero feminino em relação aos do genêro masculino, tanto no quesito nota como no quesito percentagem de faltas, Zenorini e Santos (2003) afirmam que indivíduos do gênero feminino são mais direcionados à aprendizagem como meta. Para Glewwe, Hanushek, Humpage e Ravina (2011), estudantes da área de negócios, seja em Contabilidade ou correlatas, que auferem bons resultados na sala de aula, tendem a ter bons desempenhos profissionais como aumento da renda e maior produtividade.

Pela necessidade que se tem de se compreender o processo de aprendizagem, vários pesquisadores em psicologia procuram explicações para o que pode afetar o desempenho dos estudantes. Assim encontram-se algumas respostas como otimismo, motivação do aluno, personalidade, experiência no trabalho e variáveis psicológicas (Miranda, Lemos, Oliveira \& Ferreira. 2015).

Sobre os discentes reprovados, mesmo tendo acesso às metodologias ativas, Zenori, Santos, Monteiro (2011) afirmam que não se pode reduzir o processo de ensino-aprendizagem visando apenas a "boas notas", uma vez que nem sempre tirar uma boa nota significa a verdadeira aprendizagem do discente.

Setton (1999) possibilita discutir ainda que, com a expansão de oferta ao acesso da graduação no País, ocorreu uma diversidade de populações econômicas, social e culturalmente diferenciada, impactando o processo de ensino-aprendizagem. Há de se considerar, no entanto, que, no sistema educacional brasileiro, são encontrados problemas como a não capacitação docente adequada, precariedade de infraestrutura e das metodologias utilizadas, principalmente na rede pública, o que reflete um dilema de como preparar os alunos do ensino médio público (grande maioria neste estudo) para o ensino superior (Zenori, Santos, \& Monteiro, 2011). Para Zenori, Santos e Monteiro (2011), a deficiência é vista já no ensino médio quando se percebem alunos de naturezas tão diferentes migrando para o ensino superior - algumas vezes até minimamente alfabetizados.

\section{Considerações Finais}

O objetivo geral do presente trabalho foi verificar se a adoção de metodologias ativas de ensino no curso de Ciências Contábeis de uma Instituição de Ensino Superior privada, situada na região da Zona da Mata mineira, contribuiu para o desempenho dos discentes desse curso. Para o alcance do objetivo geral, foram utilizadas como proxies para desempenho todas as variáveis fornecidas pela IES pesquisada.

A contribuição deste estudo para a academia e a sociedade torna-se relevante ao ampliar as pesquisas na área da educação contábil sobre a utilização das metodologias ativas de ensino-aprendizagem nos cursos de graduação em Contabilidade, vista a necessidade de novas discussões acerca da educação na área das Ciências Contábeis (Stanley \& Marsden, 2012)

Em relação às metodologias ativas, corroboram Bandura (1977, apud Miranda et. al. (2015)) e Ribeiro (2000, apud Miranda et. al. (2015)), que a psicologia comportamental vem mostrando que o desempenho docente tem ligação com o controle da tarefa e, quanto mais ele se sentir controlador das atividades a serem desempenhadas mais possibilidades há de ele persistir até a finalização das tarefas.

Os resultados encontrados evidenciam que quando as metodologias ativas foram implantadas, as notas dos discentes do curso de Ciências Contábeis já vinham historicamente caindo ano após ano. A partir da adoção das metodologias ativas de ensino, percebemos que, mesmo sem o aumento das notas, elas vieram ganhando maturação ao longo do período, talvez pela evolução ou pela maturidade dos professores, dos discentes ou dos responsáveis pelos treinamentos para que as atividades ativas fossem repassadas nas salas. 
Ainda, descobriu-se que, embora a nota dos discentes reprovados tenha caído com as aulas dadas com a metodologia ativa, a diferença média das notas dos aprovados para os reprovados também caiu. Outra contribuição da metodologia ativa está relacionada ao percentual de faltas dos discentes de Contabilidade, pois percebemos que, quando este foi testado, fora obtidos resultados positivos com a metodologia ativa, no modelo de regressão, quando houve redução do percentual de faltas dos discentes que receberam as metodologias ativas - mesmo os reprovados -, sugerindo que. permaneceram mais na sala de aula com a nova metodologia.

Estar em sala de aula, por exemplo, pode ter contribuído para que, a partir de 2014, as notas dos discentes, embora não melhorassem, se mantivessem constantes. Sendo assim, os resultados encontrados evidenciam que há contribuição das metodologias ativas no desempenho dos discentes do curso de Ciências Contábeis para o período estudado. Com base nos resultados, há indícios para aceitarmos a hipótese alternativa (H1), ou seja, há impacto no desempenho dos discentes do curso de Ciências Contábeis após a implantação de metodologias ativas na IES pesquisada.

É fato que esta pesquisa possui limitações, tais como: o período de análise, o ensino recebido antes da graduação (Mainardes \& Domingues, 2010), a relação dos discentes com a prática contábil (Mamede et. al., 2015), uma vez que metodologias ativas colocam o indivíduo bem próximo da realidade profissional (Gasque, 2008; Mitre et. al., 2008; Lapina \& Slaidins, 2014) e as características individuais de cada perfil (Neves Junior \& Rocha, 2010).

Vale ressaltar que, para que essas metodologias ativas de ensino possam ser aplicadas em cursos de graduação, existem alguns desafios de estrutura - acadêmica e administrativa - e de crenças dos professores e dos alunos, que devem estar envolvidos nesse processo (Wall, Prado \& Carraro, 2008) Assim, faz-se necessário que o indivíduo se empenhe em pensar, raciocinar, observar, e refletir independentemente de qual caminho será usado para provocar a aprendizagem ativa (Barbosa \& Moura, 2014)

Sugere-se que novas pesquisas sejam realizadas, considerando outras variáveis de controle na IES pesquisada ou em instituições de ensino que fazem parte do STHEM Brasil, ou ainda, em demais instituições que se utilizam das metodologias ativas nas aulas tradicionais, para se conhecerem novos resultados em cursos de Ciências Contábeis ou de outra área de ensino.

\section{Referências}

Barbosa, E. F. \& Moura, D. G. (2014). Metodologias ativas de aprendizagem no ensino de engenharia. Anais International Conference on Engineering and Technology Education, Cairo, Egito, 13.

Berbel, N. A. N. (2011). As metodologias ativas e a promoção da autonomia de estudantes. Semina: Ciências Sociais e Humanas, 32(1), pp. 25-40. doi: http://dx.doi.org/10.5433/1679-0383.2011v32n1p25

Bonwell, C. C. \& Eison, J. A. (1991). Active learning: creating excitement in the classroom. ASHE-ERIC higher education reports. ERIC Clearinghouse on Higher Education, The George Washington University, Washington, DC.

Bzuneck, J. A. (2005). A motivação dos alunos em cursos superiores. In: Joly, M. C. R. A., Santos, A. A. A. \& Sisto, F. F. (Orgs.). Questões do cotidiano universitário. São Paulo: Casa do Psicólogo, pp. 217-237.

Cornachione Junior. E. B.; Cunha, J.V.A. da; De Luca, M.M.M. \& Ott, E. (2010). O bom é meu, o ruim é seu: perspectivas da teoria da atribuição sobre o desempenho acadêmico de alunos da graduação em Ciências Contábeis. Revista Contabilidade e Finanças, 21(53), pp. 1-24. doi: http://dx.doi. org/10.1590/S1519-70772010000200004

Cyrilo, E. G. \& Toralles-Pereira, M. L. (2004). Trabalhando com estratégias de ensino-aprendizado por descoberta na área da saúde: a problematização e a aprendizagem baseada em problemas. Caderno de Saúde Pública, 20(3), pp. 780-788. doi: http://dx.doi.org/10.1590/S0102-311X2004000300015 
Dancey, C. P. \& Reidy, J. (2006). Estatística sem matemática: para psicologia usando SPSS para Windows. Porto Alegre: Artmed.

Freire, P. (1996). Pedagogia do oprimido. São Paulo: Paz e Terra.

Gasque, K. C. G. D. (2008). O papel da experiência na aprendizagem: perspectivas na busca e no uso da informação. TransInformação, Campinas, 20(2), pp. 149-158. http://dx.doi.org/10.1590/S010337862008000200003

Glewwe, P. W., Hanushek, E.A.; Humpage, S.D. \& Ravina, R. (2011). School resources and educational outcomes in developing countries: a review of the literature from 1990 to 2010. National Bureau of Economic Research.

Goñi Zabala, J. M. (2006). El espacio europeo de educación superior, un reto para la universidad. Revista Interuniversitaria de Formación del Profesorado, 20(3), pp. 323-324.

Guimarães, S. E. R. (2003). Avaliação do estilo motivacional do professor: adaptação e validação de um instrumento. Tese de Doutorado, Universidade Estadual de Campinas, Campinas, SP, Brasil.

Gwee, M. C.-E. (2009). Problem-based learning: a strategic learning systhemdesign for the education of healthcare professionals in the $21^{\text {ST }}$ Century. The Kaohsiung Journal of Medical Sciences, 25(5), pp. 231-239. doi: 10.1016/S1607-551X(09)70067-1.

Heagy, C. \& Lehmann C. (2005). Is PBL an improved delivery method for the accounting curriculum? In: Schwartz, B. \& Ketz, J. (Eds.). Advances in accounting education teaching and curriculum innovations. London: Elsevier. pp. 221-251.

Lapina, G. \& Slaidins, I. (2014). Teaching open innovation at the universities in Latvia. Journal of Business Management, (8), pp. 198-207.

Madruga, A. et al. (1996). Aprendizagem pela descoberta frente à aprendizagem pela recepção: a teoria da aprendizagem verbal significativa. In: Coll, C., Palácios, J. \& Marchesi, A. (Orgs.). Desenvolvimento psicológico e educação. Porto Alegre: Artes Médicas. pp. 68-78.

Mainardes, E. W. \& Domingues, M. J. C. S. (2010). Atração de alunos para a graduação em Administração em Joinville-SC: estudo multicaso sobre os fatores relacionados ao mercado de trabalho. FACEF Pesquisa-Desenvolvimento e Gestão, 13(1), pp. 32-47.

Mamede, S. P. N., Marques, A. V. C. \& Rogers, P. (2015). Psychological determinants of academic achievement in accounting: evidence from Brazil. BBR - Brazilian Business Review, Vitória, 12(5), pp. 50-71. DOI: http://dx.doi.org/10.15728/bbrconf.2015.3

Meyers, C. \& Jones, T. B. (1993). Promoting active learning: strategies for the college classroom. Jossey-Bass. Inc.

Miranda, G. J.; Lemos, K.C. S.; Oliveira, A.S. de \& Ferreira, M. A. (2015). Determinantes do desempenho acadêmico na área de negócios. Revista Meta: Avaliação, 7(20), pp. 175-209.

Mitre, S. M.; Siqueira-Batista, R.; Girardi-de-Mendonça, J.M.; Moaris-Pinto, N.M. de; Meirelles, C.A.B.; Pinto-Porto, C.; Moreira, T. \& Hoffmann, L.M.A. (2008). Metodologias ativas de ensino-aprendizagem na formação profissional em saúde: debates atuais. Ciência \& Saúde Coletiva, 13(2), pp. 21332144. http://dx.doi.org/10.1590/S1413-81232008000900018.

Neves Junior, I. J. \& Rocha, H. M. (2010). Metodologias de ensino em Contabilidade: uma análise sob a ótica dos estilos de aprendizagem. Anais Encontro da Associação Nacional de Pós-graduação e Pesquisa em Administração. Rio de Janeiro, RJ, Brasil, 34.

Nihalani, M. \& Shah, S. (2012). Stress free environment in classroom: impact of humor in student satisfaction. Recuperado em 20 junho, 2014, de <http://www.grin.com/en/ebook/192216/stress-free-environment-in-classroom-impact-of-humorin-student-satisfaction\#inside $>$. 
Ruiz, V. M. (2005). Aprendizagem em universitários: variáveis motivacionais. Tese de Doutorado, Pontifícia Universidade Católica, Campinas, SP, Brasil.

Setton, M. G. J. (1999). A divisão interna do campo universitário: uma tentativa de classificação. Revista brasileira de estudos pedagógicos, 80(196), pp. 451-471.

Silberman, M. (1996). Active learning: 101 strategies to teach any subject. Boston: Prentice-Hall.

Silva Souza, C., Iglesias, A. G. \& Pazin-Filho, A. (2014). Estratégias inovadoras para métodos de ensino tradicionais-aspectos gerais. Medicina (Ribeirao Preto. Online), 47(3), pp. 284-292.

Soares, M. A. (2008). Aplicação do método de ensino problem based learning (PBL) no curso de ciências contábeis: um estudo empírico. Dissertação de Mestrado, Universidade de São Paulo, São Paulo, SP, Brasil.

Soares, M. A., Araújo, A. M. P. \& Leal, E. (2008). A. Evidências empíricas da aplicação do método Problem-Based Learning (PBL) na disciplina de contabilidade intermediária do curso de Ciências Contábeis. Anaias do Encontro da Associação Nacional de Pós-graduação e Pesquisa em Administração, Rio de Janeiro, RJ, Brasil, 32.

Souza, R. R. (2000). Aprendizagem colaborativa em comunidades virtuais. Dissertação de Mestrado, Universidade Federal de Santa Catarina, Florianópolis, SC, Brasil.

Stanley, T. A. \& Marsden, S. J. (2012). Problem-based learning: does accounting education need it? Journal of Accounting Education, 30(3-4), pp. 267-289. doi:10.1016/j.jaccedu.2012.08.005

Sthem Brasil (2015). O consórcio. Recuperado 7 setembro, 2015 de $<$ http://sthembrasil.com/site/o-consorcio/>.

Wall, M. L., Prado, M. L. \& Carraro, T. E. (2008). A experiência de realizar um estágio docência aplicando metodologias ativas. Acta Paul Enferm, 21(3), pp. 515-9. doi: http://dx.doi.org/10.1590/S010321002008000300022

Weiner, B. (1982). An attributional approach for educational psychology. Review of research in education, 4(1), pp. 179-209. doi:10.3102/0091732X004001179

Zenorini, R. P. C. \& Santos, A. A. A. (2003). A motivação e a utilização de estratégias de aprendizagem em universitários. In: Mercuri, E. \& Polydoro, S. A. J. (Orgs.). Estudante universitário: característica e experiências de formação. Taubaté: Cabral Editora e Livraria Universitária.

Zenorini, R. P. C., Santos, A. A. A. \& Monteiro, R. M. (2011). Motivação para aprender: relação com o desempenho de estudantes. Paidéia, 21(49), pp. 157-164. doi:http://dx.doi.org/10.1590/S0103$-863 \mathrm{X} 2011000200003$ 